\title{
Fluid Shear Stress Differentially Modulates Expression of Genes Encoding Basic Fibroblast Growth Factor and Platelet-derived Growth Factor B Chain in Vascular Endothelium
}

\author{
Adel M. Malek, * Gary H. Gibbons," Victor J. Dzau," and Seigo Izumo ** \\ ${ }^{*}$ Harvard Medical School-Massachusetts Institute of Technology, Division of Health Sciences and Technology and ${ }^{\ddagger}$ Molecular Medicine \\ and Cardiovascular Divisions, Beth Israel Hospital, Boston, Massachusetts 02215; and ${ }^{\$}$ Cardiovascular Research Center, \\ Stanford University Medical School, Stanford, California 94305
}

\begin{abstract}
Fluid shear stress has been shown to be an important regulator of vascular structure and function through its effect on the endothelial cell. We have explored the effect of shear stress on the expression of the heparin-binding growth factors platelet-derived growth factor B chain (PDGF-B) and basic fibroblast growth factor (bFGF) in bovine aortic endothelial cells using a purpose-built cone-plate viscometer. Using morphometric analysis, we have mimicked the endothelial cell shape changes encountered in vivo in response to shear stress and correlated these with changes in gene expression. Steady laminar shear stress of 15 and $36 \mathrm{dyn} / \mathrm{cm}^{2}$ both resulted in endothelial cell shape change, but the higher shear stress induced greater and more uniform alignment in the direction of flow and nuclear protrusion after $24 \mathrm{~h}$. Steady laminar shear stress of both 15 and $36 \mathrm{dyn} / \mathrm{cm}^{2}$ induced a significant 3.9- and 4.2-fold decrease, respectively, in PDGF-B mRNA at 9 h. In contrast, steady laminar shear of $15 \mathrm{dyn} / \mathrm{cm}^{2}$ induced a mild and transient 1.5-fold increase in bFGF mRNA while shear of $36 \mathrm{dyn} /$ $\mathrm{cm}^{2}$ induced a significant 4.8-fold increase at $6 \mathrm{~h}$ of shear which remained at 2.9-fold at $9 \mathrm{~h}$. Pulsatile and turbulent shear stress showed the same effect as steady laminar shear stress (all at 15 dyn $/ \mathrm{cm}^{2}$ time-average magnitude) on PDGF-B and bFGF mRNA content. Cyclic stretch ( $20 \%$ strain, $20 / \mathrm{min}$ ) of cells grown on silicone substrate did not significantly affect either PDGF-B or bFGF mRNA levels. These results suggest that expression of each peptide growth factor gene is differentially regulated by fluid shear stress in the vascular endothelial cell. These results may have implications on vascular structure and function in response to hemodynamic forces and present a model for the study of transduction of mechanical stimuli into altered gene expression. (J. Clin. Invest. 1993.92:2013-2021.) Key words: cell shape $\bullet$ gene regulation - growth factors $\bullet$ mechanical stress • shear stress • vascular remodeling
\end{abstract}

\section{Introduction}

It has been proposed that the structure and the internal caliber of the blood vessel are intimately linked to the hemodynamic forces to which it is subjected (1). The flow of blood, a viscous

Address reprint requests to Dr. Seigo Izumo, Molecular Medicine Unit, Beth Israel Hospital, 330 Brookline Avenue, Boston, MA 02215. 1993

Received for publication 4 January 1993 and in revised form 9 April

J. Clin. Invest.

(c) The American Society for Clinical Investigation, Inc.

$0021-9738 / 93 / 10 / 2013 / 09 \$ 2.00$

Volume 92, October 1993, 2013-2021 fluid, is associated with shear stress, the tractive force per unit area, which acts in the direction of blood flow on the surface of the inner wall of the blood vessel at the endothelial cell. In the simplifying case of fully developed laminar Poiseuille-Hågen flow, the wall shear stress is proportional to the flow velocity and medium viscosity and inversely proportional to the third power of the internal radius (Fig. $1 A$ ) (2). Theoretical and experimental studies have suggested that an optimally designed arterial circulation is characterized by a constant wall shear stress $(1,3)$. Experiments using surgically induced increases in blood flow have resulted in an increase in endothelial cell density, elongation, and nuclear protrusion (4), followed by longterm compensatory structural expansion and increase in internal radius such that wall shear stress is returned to its preoperative value of $\sim 15 \mathrm{dyn} / \mathrm{cm}^{2}$ (5). Conversely, experiments in which blood flow, and consequently shear stress, was decreased resulted in a long-term reduction in internal radius bringing shear stress to its baseline level by a process that was dependent on intact endothelium (6).

The distribution of hemodynamic forces and shear stress has also been implicated in the focal nature and higher preponderance of early atherosclerotic lesions on the outer segments of bifurcations which are characterized by shear stress that is time-varying and of low magnitude $\left(\sim 4 \mathrm{dyn} / \mathrm{cm}^{2}\right)$ rather than on the inner segments which are exposed to shear stress of higher magnitude ( $\sim 15 \mathrm{dyn} / \mathrm{cm}^{2}$ and above $)$ and less temporal fluctuations $(7,8)$. Furthermore, smooth muscle cell proliferation and neointimal thickening in synthetic vascular grafts has also been shown to be higher at lower shear stress magnitude (9). These results point to the effect of fluid shear stress acting on the endothelium as an important determinant of vascular tissue structure and function both in development and in pathophysiological states. The mechanism of fluid shear-mediated changes in vascular structure is currently not well understood.

Although the effect of inflammatory mediators and cytokines on endothelial cell function has been extensively characterized, little is known about the effect of shear stress, to which endothelium is constantly subjected in vivo, on endothelial gene expression. Such studies are important because fluid shear stress may be the most significant physiological regulator of endothelial function. Furthermore, the endothelial cell has already been shown to be sensitive to fluid shear stress, to which it responds by increases in intracellular calcium release $\left[\mathrm{Ca}^{2+}\right]_{i}$ by both an ATP-dependent $(10,11)\left(\Delta\left[\mathrm{Ca}^{2+}\right]_{\mathrm{i}}=100-400\right.$ $\mathrm{nM})$ and ATP-independent $\left(\Delta\left[\mathrm{Ca}^{2+}\right]_{\mathrm{i}}=75 \mathrm{nM}\right.$ (12) mechanism in bovine aortic endothelial (BAE) ${ }^{1}$ cells. Earlier experi-

1. Abbreviations used in this paper: BAE, bovine aortic endothelial (cells); bFGF, basic fibroblast growth factor; ERDF, endothelial-derived relaxing factor; ET-1, endothelin-1; GAPDH, glyceraldehyde3-phosphate dehydrogenase; tPA, tissue plasminogen activator. 
A)
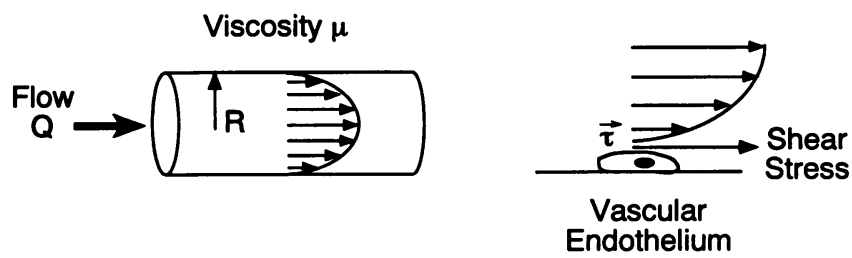

\section{Hagen-Poiseuille Law}

Wall Shear Stress $=\tau=\left(\frac{4 \mu Q}{\pi R^{3}}\right)$

B)

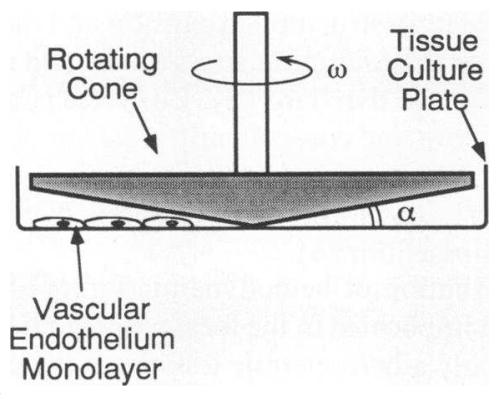

Figure 1. (A) Hågen-Poiseuille equation for wall shear stress assuming fully developed laminar flow, $Q$, of a fluid of viscosity, $\mu$, in a blood vessel of internal radius $R$. The velocity profile is a parabola and the wall shear stress vector acts on the surface of the endothelial cell. Note that the shear stress magnitude is proportional to flow and viscosity but inversely proportional to the third power of vessel radius, thus allowing the maintenance of a constant shear stress in the face of large variations in blood flow by small compensations in vessel radius. $(B)$ Schematic of cone-plate viscometer apparatus employing standard plastic tissue culture plates. A cone of shallow angle ( $\alpha$ between 0.5 and $5^{\circ}$ ) in contact at its tip with the center of the tissue culture plate rotates at $\omega$ radians/s, thereby imparting shear stress on the confluent monolayer of endothelial cells grown on the plate's surface. The shear stress magnitude is computed as described in the Methods section.

ments have indicated that shear stress can double the levels of inositol trisphosphate (13) and increase the incorporation of arachidonic acid into diacylglycerol in human vascular endothelium (14). Shear stress also induces decreases in intracellular $\mathrm{pH}$ (15), elaboration of actin stress fibers (16), cell shape change (17), release of endothelial-derived relaxing factor (EDRF) (18), increases in tissue plasminogen activator (tPA) secretion (19), and decreases in endothelin-1 (ET-1) mRNA and peptide release $(20,21)$.

We hypothesized that fluid shear stress in the physiological range may affect the expression of polypeptide growth factor production by the endothelial cell as part of a feedback loop of vascular structural control. We chose to investigate the effect of fluid shear stress applied in vitro to confluent monolayers of BAE cells on the mRNA expression of basic fibroblast growth factor (bFGF) and platelet-derived growth factor B-chain (PDGF-B). bFGF and PDGF-B are potent heparin-binding polypeptide growth factors (22) with important chemotactic and mitogenic properties that have been proposed as key players in determining vascular structural response in models of injury (23) and atherosclerosis $(24,25)$. bFGF is mitogenic to endothelial and smooth muscle cells, and is a powerful angiogenic factor that is associated with the extracellular matrix and basement membrane (26). Although it does not possess a signal sequence for export via the classical endoplasmic reticulum-Golgi pathway, it has been demonstrated to be released by cell injury (27) in certain tumors (28) and by other yet undetermined mechanisms (29). PDGF is a mitogen, smooth muscle cell chemoattractant and vasoconstrictor $(30,31)$; it exists as a dimeric molecule consisting of two chains $A$ and $B$ derived from distinct genes that bind to dimeric receptors consisting of $\alpha$ and $\beta$ subunits forming three subtypes $(\alpha \alpha, \alpha \beta, \beta \beta)(30)$. PDGF, unlike bFGF which is mostly cell-associated and has a high affinity for the extracellular matrix, is secreted by the endothelial cell.

We hypothesized that physiological fluid shear stress may result in a decreased production of PDGF-B in light of our previous observations of shear-induced downregulation of ET1 (20), which shares with PDGF-B the property of vasoconstriction and smooth muscle mitogenesis $(32,33)$. We also hypothesized that shear stress may affect the expression of bFGF in light of the findings of increased endothelial density in response to step increases to high flow and resulting high shear stress (4). We have evaluated the in vitro effect of fluid shear stress of physiological moderate $\left(15 \mathrm{dyn} / \mathrm{cm}^{2}\right)$ and elevated $\left(36 \mathrm{dyn} / \mathrm{cm}^{2}\right.$ ) magnitude on the morphological properties and extent of cell shape change in confluent BAE monolayers and on mRNA levels of PDGF-B and bFGF using a previously described cone-plate apparatus (20). We have also evaluated the effect of altering the temporal characteristics of the shear stress stimulus at a fixed magnitude by using steady laminar, pulsatile, and turbulent shear.

\section{Methods}

Cell culture. BAE cells were harvested from descending thoracic aortas obtained from the local abattoir by collagenase digestion, and were used between passages 6 and 15. The cells were cultured in growth medium consisting of Dulbecco's modified Eagle (DME) medium (Gibco, Grand Island, NY) supplemented with $10 \%$ calf serum (Gibco), $4 \mathrm{mM}$ L-glutamine, $25 \mathrm{mM}$ Hepes, $\mathrm{pH} 7.4,10 \mathrm{U} / \mathrm{ml}$ of penicillin, and $10 \mu \mathrm{g} / \mathrm{ml}$ of streptomycin, at $37^{\circ} \mathrm{C}, 5 \% \mathrm{CO}_{2}$ in a humidified incubator.

Shear stress and cyclic stretch apparatus. Confluent cells in 10-cm standard tissue culture plates were fed with growth medium (see above) $24-48 \mathrm{~h}$ before onset of stimulus and then exposed to fluid shear stress using a purpose-built cone-plate viscometer specifically designed to accept standard tissue culture plates (Fig. $1 \mathrm{~B}$ ) at $37^{\circ} \mathrm{C}$ and a humidified atmosphere of $5 \% \mathrm{CO}_{2}(20)$. Four different shear stress regimens were achieved: steady laminar shear at 15 and $36 \mathrm{dyn} / \mathrm{cm}^{2}$, turbulent shear stress at a mean of $15 \mathrm{dyn} / \mathrm{cm}^{2}$ and pulsatile shear stress at a mean of $15 \mathrm{dyn} / \mathrm{cm}^{2}$. Reynolds number, $R$, and fluid shear stress magnitude, $\tau_{\mathrm{ss}}$, were computed at different values of radius $r$ as shown in Eqs. 1 and 2 below according to Sdougos et al. (34):

$R=\frac{r^{2} \omega \alpha^{2}}{12 \nu}$ 


$$
\left|\tau_{\mathrm{ss}}\right| \sim\left(\frac{\mu \omega}{\alpha}\right)\left[1+2.58\left(\frac{R^{3 / 2}}{3.5+R}\right)-0.86\left(\frac{R^{5 / 2}}{(3.5+R)^{2}}\right)\right]
$$

where $\mu$ is viscosity, $\nu$ is kinematic viscosity, $\omega$ is rotational velocity, and $\alpha$ is the cone angle. Static viscosity of the medium, obtained by measuring kinematic viscosity using a calibrated Canon-Fenske type viscometer (Fisher Scientific Co., Pittsburgh, PA) and multiplying by the density of the medium, was 0.76 centipoise at $37^{\circ} \mathrm{C}$. Average Reynolds number and shear stress magnitude were obtained by integrating their respective value over the area of the tissue culture plate. In the steady laminar mode, a cone of $1^{\circ}$ angle spinning at 4 revolutions/s was used to achieve an average shear stress magnitude of $\tau=15 \pm 0.41$ $\mathrm{dyn} / \mathrm{cm}^{2}$ (average $\pm \mathrm{SD}$ ) and Reynolds number $R=0.69 \pm 0.06$, while in other experiments a cone of $0.5^{\circ}$ angle spinning at either 2.7 or 6 revolutions/s was chosen to obtain, respectively, $\tau=15.2 \pm 0.05$ dyn/ $\mathrm{cm}^{2}$ with $R=0.12 \pm 0.01$, and $\tau=36 \pm 0.36 \mathrm{dyn} / \mathrm{cm}^{2}$ with $R$ $=0.26 \pm 0.02$. Turbulent shear stress of magnitude $15 \pm 0.90 \mathrm{dyn} / \mathrm{cm}^{2}$ was attained by use of a cone of angle $5^{\circ}$ rotating at 4 revolutions $/ \mathrm{s}$ resulting in $R=17.2 \pm 1.57$. In order to achieve pulsatile shear, a modified cone varying sinusoidally in angle between $0.4^{\circ}$ and $0.6^{\circ}$ rotating at 2.5 revolutions/s provided average shear stress magnitude ranging between $12 \pm 0.06$ and $18 \pm 0.29 \mathrm{dyn} / \mathrm{cm}^{2}\left(\right.$ mean $\left.=15 \mathrm{dyn} / \mathrm{cm}^{2}\right)$ at a frequency of $2.5 \mathrm{~Hz}$ as previously described (20) with corresponding Reynolds numbers of $R=0.07 \pm 0.01$ and $0.16 \pm 0.01$, respectively. Measurements of lactic dehydrogenase release showed no significant increase in the media of cells exposed to any mode of shear stress used in this study as compared to control (data not shown) suggesting absence of shear-induced cell injury.

BAE cells were seeded on type I collagen-treated silicone membranes grown to confluent monolayers then exposed to uniaxial cyclic stretch of $20 \%$ strain at a rate of $20 /$ min (courtesy of Dr. Thomas Kulik, University of Michigan, Ann Arbor). Monolayers were then lysed and processed for Northern blot analysis of RNA.

Cell morphology analysis. After exposure of BAE monolayers to steady laminar shear stress of magnitude 15 or $36 \mathrm{dyn} / \mathrm{cm}^{2}$ for $24 \mathrm{~h}$, cells were visualized on an inverted microscope (model IMT-2, Olympus Corp., Lake Success, NY) using both phase contrast and Hoffman optics and were photographed using T-Max 400 film (Eastman Kodak Co., Rochester, NY). Images were then scanned two-dimensionally to serve as input into the image and shape analysis software. Cell contour was traced manually and connectivity analysis was carried on the resulting set of blobs using the Image Analyst software package (Automatix, Billerica, MA) on a Macintosh II/fx system (Apple Computer, Cupertino, CA ). The algorithm determined the best-fit ellipse through each cellular contour and provided the corresponding angle of direction of ellipse's major axis as well as the roundness values for each cellular contour, with 1 representing a perfect circle and 0 a line.

$R N A$ isolation and hybridization. The acid guanidium thiocyanate phenol chloroform method (35) was used to isolate total cellular RNA. After determination of RNA purity and concentration, $25 \mu \mathrm{g}$ of total RNA was fractionated using $1.2 \%$ agarose gels containing $6 \%$ formaldehyde, $0.02 \mathrm{M}$ 3-( $N$-morpholino)propanesulfonic acid, $0.005 \mathrm{M}$ sodium acetate, and $0.001 \mathrm{M}\left(\mathrm{Na}^{+}\right) 2 \cdot$ EDTA. RNA was then transferred overnight by capillary action in $10 \times \operatorname{SSC}(1.5 \mathrm{M}$ sodium chloride, 0.15 $\mathrm{M}$ sodium citrate, $\mathrm{pH} 7$ ) onto GeneScreen membranes (New England Nuclear, Boston, MA), and immobilized by ultraviolet (UV) irradiation. Prehybridization and hybridization of the membranes was accomplished in $50 \%$ formamide, $0.2 \%$ polyvinylpyrrolidone, $0.2 \%$ bovine serum albumin, $0.2 \%$ Ficoll, $0.05 \mathrm{M}$ tris(hydroxymethyl)-aminomethane $\cdot \mathrm{HCl}(\mathrm{pH} 7.5), 1 \mathrm{M} \mathrm{NaCl}, 0.1 \%$ sodium pyrophosphate, $1 \%$ sodium dodecyl sulfate, $10 \%$ dextran sulfate, $100 \mu \mathrm{g} / \mathrm{ml}$ of denatured salmon sperm DNA, and $1 \mu \mathrm{g} / \mathrm{ml}$ of poly (A) and poly (C). Northern blot hybridization was performed with a random-primer ${ }^{32} \mathrm{P}$-labeled 1.4-kb EcoRI cDNA fragment of bovine bFGF (36) (kind gift of Dr. J. Fiddes, California Biotechnology, Mountain View, CA), 1.2-kb Sal IXbal fragment of c-sis cDNA (37), 0.9-kb EcoRI fragment of PDGF-A cDNA (38) (kind gifts of Dr. M. Mercola, Dana Farber Cancer Institute, Boston) and 1.3-kb Pst I fragment of rat glyceraldehyde-3-phos- phate dehydrogenase (GAPDH) cDNA. After incubation, the blots were washed in $2 \times$ SSC- $1 \%$ SDS for $15 \mathrm{~min}$ at room temperature then in $0.2 \times$ SSC- $1 \%$ SDS for $15 \mathrm{~min}$ at room temperature followed by three washes of $20 \mathrm{~min}$ in $0.2 \times \mathrm{SSC}-1 \% \mathrm{SDS}$ at $55^{\circ} \mathrm{C}$ for bFGF and PDGF- $\beta$, at $63^{\circ} \mathrm{C}$ for GAPDH, and then exposed to X-ray film (X-Omat-AR film, Kodak) at $-80^{\circ} \mathrm{C}$. Autoradiograms exposed in the linear range of the $\mathrm{X}$-ray films were scanned by a densitometer two-dimensionally and the signal strength of either bFGF or PDGF B-chain mRNA was normalized for each sample with respect to the density of the corresponding GAPDH mRNA signal, to compensate for potential variation in RNA loading and transfer. GAPDH mRNA was chosen because its level is not affected by fluid shear stress (20) (and see Results). For quantitation of bFGF mRNA, the major 7-kb band was used for densitometry (see Fig. $5 \mathrm{~B}$ ). Qualitatively similar results were obtained when the 4.0- or 1.9-kb bands were used (data not shown).

Statistics. Data were expressed as mean \pm SEM, except for computation of shear stress magnitude, Reynolds number, and major axis of cells where $\mathrm{SD}(\sigma)$ was computed where indicated. Statistical analysis was performed by analysis of variance and the unpaired Student $t$ test.

\section{Results}

Cell alignment and morphology. Application of physiological fluid shear stress has been previously shown to induce endothelial cell shape change resulting in alignment. To characterize cell morphological changes at physiological moderate and elevated shear stress, we analyzed cell alignment and morphology of BAE monolayers to steady laminar shear stress of 15 and 36 dyn $/ \mathrm{cm}^{2}$ respectively for $24 \mathrm{~h}$. BAE cells aligned in the direction of flow under both conditions (Fig. 2, $B$ and $C$ ) when compared to control stationary cells (Fig. $2 A$ ). Fig. 2 also shows that when compared to the physiological moderate magnitude of arterial shear stress $\left(15 \mathrm{dyn} / \mathrm{cm}^{2}\right)$, the cells exposed to elevated shear ( $36 \mathrm{dyn} / \mathrm{cm}^{2}$ ) appear longer and narrower, and display more apparent protrusion in the nuclear area (compare Fig. 2, $B$ and $C$ ) at $24 \mathrm{~h}$. Morphometric analysis revealed that the cells exposed to $36 \mathrm{dyn} / \mathrm{cm}^{2}$ were more elongated and spindle-shaped as demonstrated by a significantly lower computed roundness ratio of $0.24 \pm 0.001(n=240, P$ $<0.001$ ) when compared to cells exposed to $15 \mathrm{dyn} / \mathrm{cm}^{2}$ whose roundness ratio was $0.43 \pm 0.001(n=266, P<0.001)$ and static control cells of roundness $0.58 \pm 0.001(n=238)$ as shown in Fig. $2 D$.

Histogram analysis showed that cells exposed to 36 dyn/ $\mathrm{cm}^{2}$ also showed a more complete and uniform alignment in the direction of flow as shown by a narrower distribution of the angle made between the major axis of a particular cell and the direction of flow. Fig. $3 \mathrm{~A}$ illustrates the random distribution of static control cells having mean angle of -1.7 and a standard deviation $\sigma=51.9^{\circ}(n=238$, Fig. $3 A)$. This is in contrast with cells exposed to $15 \mathrm{dyn} / \mathrm{cm}^{2}$ characterized by a mean angle of $9.5^{\circ} \pm \sigma=20.6^{\circ}(n=266$, Fig. $3 B)$, and cells exposed to 36 $\mathrm{dyn} / \mathrm{cm}^{2}$ with a mean angle of $5.7^{\circ} \pm \sigma=10.7^{\circ}(n=240$, Fig. 3 $C)$. Note that both populations exposed to shear stress exhibit normal distributions centered approximately around the direction of flow but that the BAE monolayers exposed to the moderate shear ( $15 \mathrm{dyn} / \mathrm{cm}^{2}$ ) had a broader distribution with nearly double the standard deviation of those exposed to elevated shear ( $36 \mathrm{dyn} / \mathrm{cm}^{2}$ ), which were characterized by a narrower distribution and more uniform alignment.

Regulation of PDGF B chain $m R N A$ by fluid shear stress. We have investigated the effect of fluid shear stress on the mRNA levels of the paracrine growth factor PDGF A and B chain. Northern blot analysis of total RNA using a cDNA 


\section{Direction of Flow}

A)

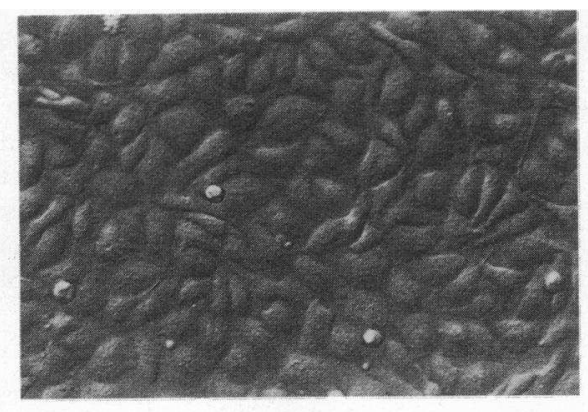

Static Control

$\tau=0$ dynes $/ \mathrm{cm}^{2}$

B)

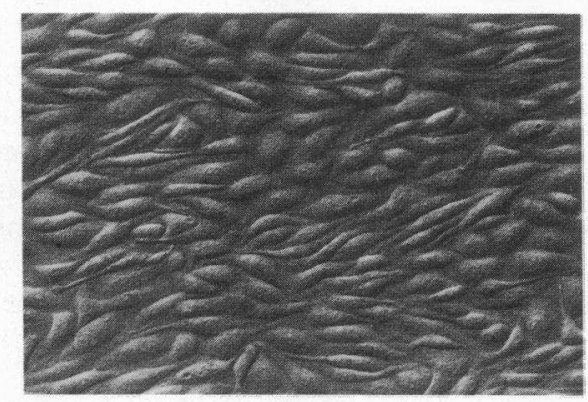

Moderate Magnitude Shear Stress $\tau=15$ dynes $/ \mathrm{cm}^{2}$

C)

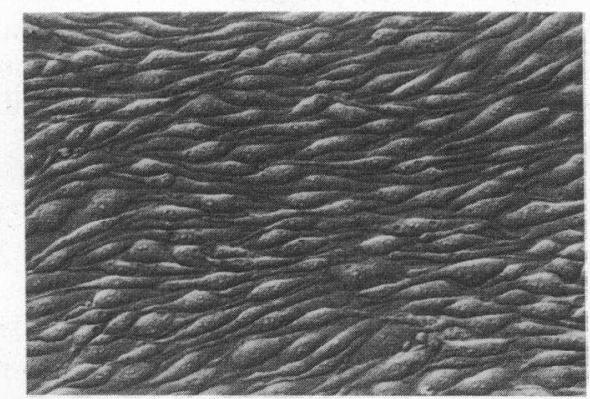

Elevated Magnitude Shear Stress $\tau=36$ dynes $/ \mathrm{cm}^{2}$

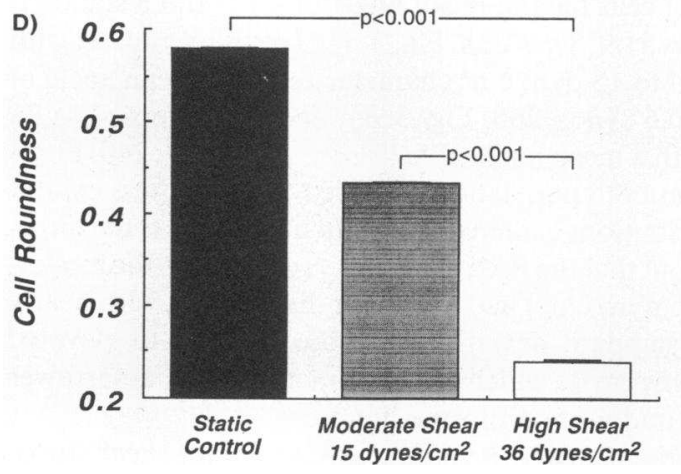

Figure 2. Hoffman modulation micrographs of BAE cells exposed to static conditions $(A)$, steady laminar shear stress of moderate magnitude $\left(15\right.$ dynes $\left./ \mathrm{cm}^{2}\right)(B)$, and steady laminar shear stress of elevated probe for PDGF-A failed to detect any measurable $\alpha$ chain mRNA in BAE cells, a finding consistent with previous observations (39). Northern blot analysis using c-sis cDNA probes for PDGF-B chain mRNA revealed that exposure of BAE cells to fluid shear stress of both 15 and $36 \mathrm{dyn} / \mathrm{cm}^{2}$ induced a mild transient increase in PDGF B-chain mRNA that peaked at 30 min and was followed by a more significant and sustained downregulation by $6 \mathrm{~h}$ ( Fig. $4 \mathrm{~A}$ ). A similar downregulation of PDGF B-chain was also observed at the higher shear stress magnitude of $36 \mathrm{dyn} / \mathrm{cm}^{2}$. Densitometric analysis (Fig. $4 \mathrm{~B}$ ) of three to nine separate experiments revealed a transient and statistically nonsignificant increase in PDGF B-chain mRNA at $30 \mathrm{~min}$ followed by a sustained decrease of 2.6-fold ( $P$ $<0.005)$ at $6 \mathrm{~h}$ and 3.9 -fold at $9 \mathrm{~h}(P<0.05)$ at $15 \mathrm{dyn} / \mathrm{cm}^{2}$. At shear stress magnitude of $36 \mathrm{dyn} / \mathrm{cm}^{2}$ PDGF-B mRNA decreased 3.6-fold at $6 \mathrm{~h}(P<0.005)$ and 4.2 -fold $(P<0.005)$ at 9 h compared to its level in matched static controls (Fig. $4 B$ ). The extent of PDGF-B mRNA change at moderate shear ( 15 dyn $/ \mathrm{cm}^{2}$ ), unlike the case of bFGF, was not significantly different from that observed at elevated shear $\left(36 \mathrm{dyn} / \mathrm{cm}^{2}\right)$. To confirm specificity of the shear stress stimulus, cyclic stretch was applied to BAE cells grown on a deformable silicone substrate. Cyclic stretch at a rate of $20 /$ min elicited a mild and transient increase in PDGF-B mRNA at 30 min, which returned to baseline and was not sustained (Fig. $4 \mathrm{~B}$ ).

Regulation of bFGF by fluid shear stress. To determine the effect of fluid shear stress on vascular endothelial mRNA levels of bFGF, confluent monolayers of BAE cells were exposed to steady laminar shear stress at both 15 and $36 \mathrm{dyn} / \mathrm{cm}^{2}$, the same magnitudes of shear used for morphometric analysis. Fig. $5 A$ shows a Northern blot of total RNA isolated from shear-exposed monolayers at increasing durations of exposure showing hybridization to three mRNA species as previously described (36) of approximate size 7.0, 4.0, and $1.9 \mathrm{~kb}$. Northern analysis of BAE monolayers exposed to laminar shear stress of 36 dyn / $\mathrm{cm}^{2}$ resulted in a significant increase in bFGF mRNA signals of all three sizes, detectable as early as $0.5 \mathrm{~h}$ and remaining elevated at $9 \mathrm{~h}$ (Fig. $5 \mathrm{~A}$, right). In contrast, cells exposed to 15 dyn $/ \mathrm{cm}^{2}$ showed a mild to moderate increase at $0.5-6 \mathrm{~h}$ as shown in Fig. $5 \mathrm{~A}$ (middle). Shear stress of neither 15 nor 36 $\mathrm{dyn} / \mathrm{cm}^{2}$ had any significant effect on GAPDH mRNA levels. Densitometric analysis of the major 7-kb transcript was performed on Northern blots from three to nine separate experiments (Fig. $5 \mathrm{~B}$ ). The results from the shear stress magnitude of $15 \mathrm{dyn} / \mathrm{cm}^{2}$ revealed a mean increase (1.5-fold) in relative bFGF mRNA between 0.5 and $6 \mathrm{~h}$ which was statistically significant $(P<0.05)$. Exposure to the higher shear stress magnitude

magnitude ( 36 dynes $/ \mathrm{cm}^{2}$ ) $(C)$ for $24 \mathrm{~h}$. Note the alignment in the direction of flow (and shear stress) and the cell shape change from polygonal cobblestone to spindle-shaped. BAE cells exposed to the 36 dynes $/ \mathrm{cm}^{2}(C)$ of shear showed significantly greater length, smaller width, and more slender ends with a protruding nuclear area compared to cells exposed to 15 dynes $/ \mathrm{cm}^{2}(B)$ and static controls $(A)$. Cell shape analysis of BAE cells $(D)$ exposed to $24 \mathrm{~h}$ of steady laminar shear stress of moderate $\left(15\right.$ dynes $\left./ \mathrm{cm}^{2}\right)$ and elevated $(36$ dynes $/ \mathrm{cm}^{2}$ ) magnitude compared to cells maintained under static conditions. Roundness ratios were computed for each cell after computation of the best-fit ellipse through the cellular contour. Data is representative of $\sim 250$ cells in each category and bars correspond to the standard error from the mean. A roundness ratio of 1 corresponds to a perfect circle while 0 corresponds to a line. 


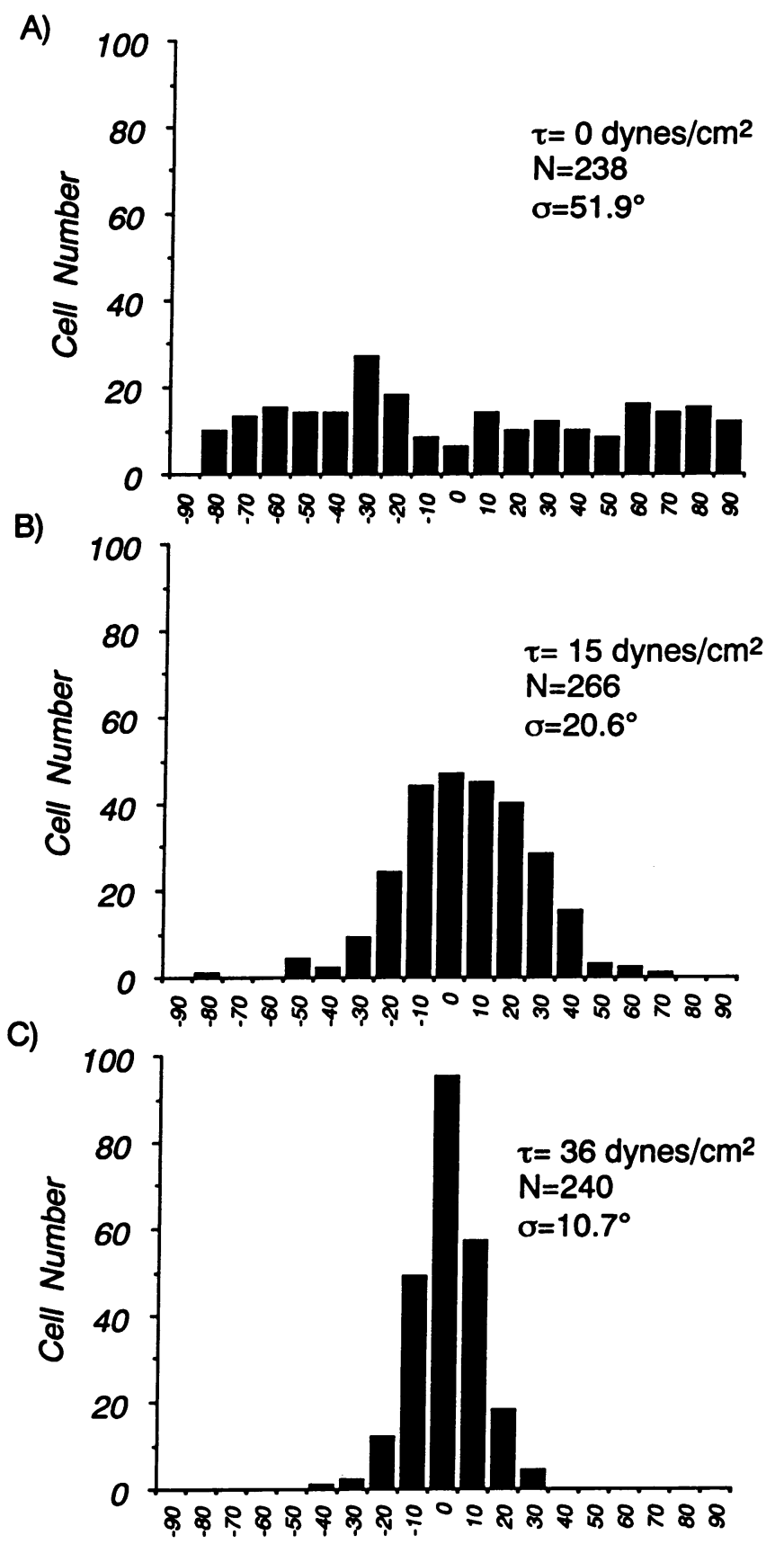

Angle of Major Axis (Degrees)

Figure 3. Histogram analysis of angle of orientation of the major axis in BAE cells exposed to $24 \mathrm{~h}$ of static conditions $(A)(n=238$ cells $)$, steady laminar shear stress of 15 dynes $/ \mathrm{cm}^{2}$ (moderate) $(n=266$ cells) and $(B) 36$ dynes $/ \mathrm{cm}^{2}$ (elevated) $(n=240$ cells) magnitude. Note that cells exposed to 36 dynes $/ \mathrm{cm}^{2}$ magnitude showed a narrower distribution $\left(\right.$ mean $\left.=5.7^{\circ} \pm \sigma=10.7^{\circ}\right)$ than those exposed to 15 dynes $/ \mathrm{cm}^{2}\left(\right.$ mean $\left.=9.5^{\circ} \pm \sigma=20.6^{\circ}\right)$ indicating a more pronounced and uniform alignment with flow. The distribution for cells under static conditions was random ( mean $\left.=-1.7^{\circ} \pm \sigma=51.9^{\circ}\right)$.

of $36 \mathrm{dyn} / \mathrm{cm}^{2}$ resulted in a mean increase of 4.2 -fold at $3 \mathrm{~h}(P$ $<0.05), 4.8$-fold at $6 \mathrm{~h}(P<0.005)$ and 2.6 -fold at $9 \mathrm{~h}(P$ $<0.05$ ) compared to static control monolayers. The bFGF remained elevated at $9 \mathrm{~h}$ although the time course suggested this might be a transient effect. To verify whether the change in bFGF mRNA levels was specific to shear stress and not to any mechanical stimulus, BAE monolayers were subjected to cyclic stretch of $20 \%$ strain at a rate of $20 / \mathrm{min}$ which showed no significant effect as shown in Fig. $5 \mathrm{~B}$.

Effect of dynamic character of shear stimulus on PDGF-B and bFGF $m R N A$ levels. In an effort to determine the effect of altering the time characteristics of the shear stress stimulus on growth factor mRNA levels, we subjected BAE monolayers to four different conditions for a duration of $6 \mathrm{~h}:(a)$ steady laminar shear stress of $15 \mathrm{dyn} / \mathrm{cm}^{2}$ (moderate), $(b)$ steady laminar shear stress of $36 \mathrm{dyn} / \mathrm{cm}^{2}$ (elevated), (c) pulsatile laminar shear stress varying between 12 and $18 \mathrm{dyn} / \mathrm{cm}^{2}$ (mean magnitude $15 \mathrm{dyn} / \mathrm{cm}^{2}$ ) at a frequency of $2.5 \mathrm{~Hz}$, and $(d)$ turbulent shear stress of mean magnitude $15 \mathrm{dyn} / \mathrm{cm}^{2}$.

A panel of the representative results for PDGF-B mRNA levels appear in Fig. 6 and indicate that steady laminar shear of 15 and $36 \mathrm{dyn} / \mathrm{cm}^{2}$ (lanes 1 and 2), turbulent (lane 5) and pulsatile laminar (lane 8 ) shear of $15 \mathrm{dyn} / \mathrm{cm}^{2}$ all resulted in decreased PDGF-B mRNA levels at $6 \mathrm{~h}$.

The corresponding results for bFGF in Fig. 7 and five separate experiments revealed no significant difference in bFGF mRNA level between steady laminar and turbulent, and between steady laminar and pulsatile laminar shear stress (all of magnitude $15 \mathrm{dyn} / \mathrm{cm}^{2}$ ) when compared to static control. Some variations in bFGF in turbulent (lane 5) and pulsatile (lane 8 ) were occasionally observed, but were not significantly different from static controls in five other experiments (data not shown). In contrast steady laminar shear stress of $36 \mathrm{dyn} /$ $\mathrm{cm}^{2}$ (lane 1 ) caused a clear increase in bFGF mRNA.

This result suggests that the magnitude of the shear stress stimulus is a more important determinant of bFGF and PDGF-B mRNA levels than the dynamic characteristics of the shear stress at a given time-average magnitude, at least for the four conditions employed in this study. These findings suggest that the endothelial cell, which may be modeled as a viscoelastic structure $(40,41)$, behaves as a sensor to the low frequency (average magnitude) of the shear stress stimulus rather than to its higher frequency components (turbulent or pulsatile). The results presented here do not rule out a different result when a shear stress stimulus of different degree of turbulence or of variation at a different frequency is used.

\section{Discussion}

There has been mounting evidence to suggest that blood flow, and more specifically the resulting shear stress acting on the vessel wall at the endothelial cell, plays a central role in determining vascular structure $(1,5,6)$ by a process that is dependent on intact endothelium (6). Recent work has also demonstrated that fluid shear stress changes physiological properties of endothelial cells $(10-12,15,42)$. There has been comparatively less known about the effect of shear stress on endothelial cell function and gene expression that may propose a link between the sensory capacity of the endothelium and the longterm changes in vascular structure in response to changes in blood flow that are known to be dependent on functional endothelium (6). In this study we have shown that fluid shear stress differentially modulates the mRNA levels of the two potent polypeptide growth factors bFGF and PDGF-B. We have shown that vascular endothelium is sensitive to the magnitude of the applied shear stress both morphologically and function- 

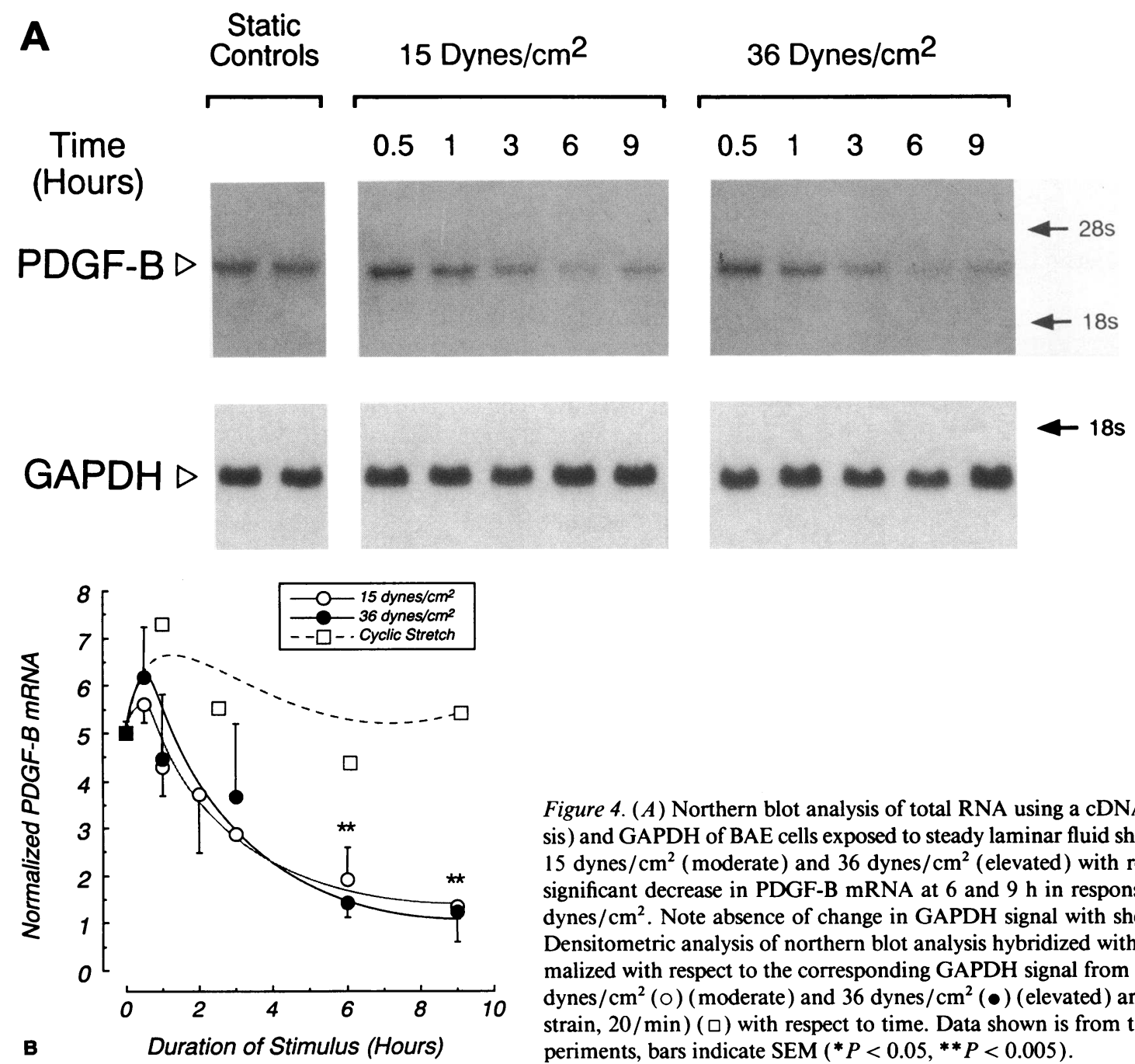

Figure 4. (A) Northern blot analysis of total RNA using a cDNA probe for PDGF-B (csis) and GAPDH of BAE cells exposed to steady laminar fluid shear stress of magnitude 15 dynes $/ \mathrm{cm}^{2}$ (moderate) and 36 dynes $/ \mathrm{cm}^{2}$ (elevated) with respect to time. Note the significant decrease in PDGF-B mRNA at 6 and $9 \mathrm{~h}$ in response to both 15 and 36 dynes $/ \mathrm{cm}^{2}$. Note absence of change in GAPDH signal with shear stress exposure. $(B)$ Densitometric analysis of northern blot analysis hybridized with PDGF-B (c-sis) normalized with respect to the corresponding GAPDH signal from BAE cells exposed to 15 dynes $/ \mathrm{cm}^{2}(0)$ (moderate) and 36 dynes $/ \mathrm{cm}^{2}(\bullet)$ (elevated) and cyclic stretch $(20 \%$ strain, 20/min) (ם) with respect to time. Data shown is from three to nine separate experiments, bars indicate SEM $\left({ }^{*} P<0.05,{ }^{* *} P<0.005\right)$.

ally. Although BAE monolayers exposed for $24 \mathrm{~h}$ to steady laminar shear stress of both 15 and $36 \mathrm{dyn} / \mathrm{cm}^{2}$ magnitude adopted a spindle shape and aligned in the direction of flow, those exposed to the higher magnitude of shear exhibited a significantly higher morphological change with increased length, decreased width, and apparent central nuclear protrusion. These shape changes at elevated shear stress are reminiscent of the results of an in vivo study reported by Masuda et al. (4) using surgically induced arteriovenous shunts to dramatically increase shear stress by a factor of 4 in the carotid artery, which demonstrated changes such as thickening of the endothelium and nuclear protrusion.

The ability of the endothelial cell to be functionally sensitive to the magnitude of the applied shear was also evident by the differential regulation of bFGF mRNA, increasing significantly at $36 \mathrm{dyn} / \mathrm{cm}^{2}$ but much less at $15 \mathrm{dyn} / \mathrm{cm}^{2}$, while PDGF-B mRNA decreased significantly and by approximately the same extent in response to both magnitudes. The importance of the magnitude of the shear stress was further underscored by the lack of sensitivity of bFGF and PDGF-B mRNA levels to time-varying shear such as turbulent and pulsatile shear of equal time-average magnitude employed here. The functional sensitivity of the endothelium to the shear stress magnitude is consistent with our previous observations of ET-1
mRNA downregulation (20), which is minimal at $4 \mathrm{dyn} / \mathrm{cm}^{2}$ but decreases four- to fivefold at and above $15 \mathrm{dyn} / \mathrm{cm}^{2}$. At present, we do not know whether there is a threshold effect of shear on PDGF-B mRNA expression. The response of bFGF observed at high shear but not low shear is qualitatively similar to that reported for the increase in tPA secretion and mRNA which is seen in human umbilical vein cells at arterial levels of shear $25 \mathrm{dyn} / \mathrm{cm}^{2}$ but not at lower venous levels of $4 \mathrm{dyn} / \mathrm{cm}^{2}$ $(19,43)$.

Since bFGF has been shown to play a role in autocrine growth regulation (44) and migration (29) of the endothelial cell, this high shear-induced increase may be relevant to the observed long-term increase in endothelial density that is observed following surgically induced increases in blood flow in the canine carotid artery arteriovenous shunt model (4). The observed increase in endothelial bFGF mRNA at higher shear could selectively act in an autocrine manner without necessarily influencing the growth of the underlying smooth muscle cells. Such a phenomenon is suggested by experiments in a rat model of intimal hyperplasia in which constant bFGF delivery at the adventitia did not affect medial smooth muscle cell growth when endothelial cells were intact but did so significantly when endothelium was removed or injured with endotoxin (45). 


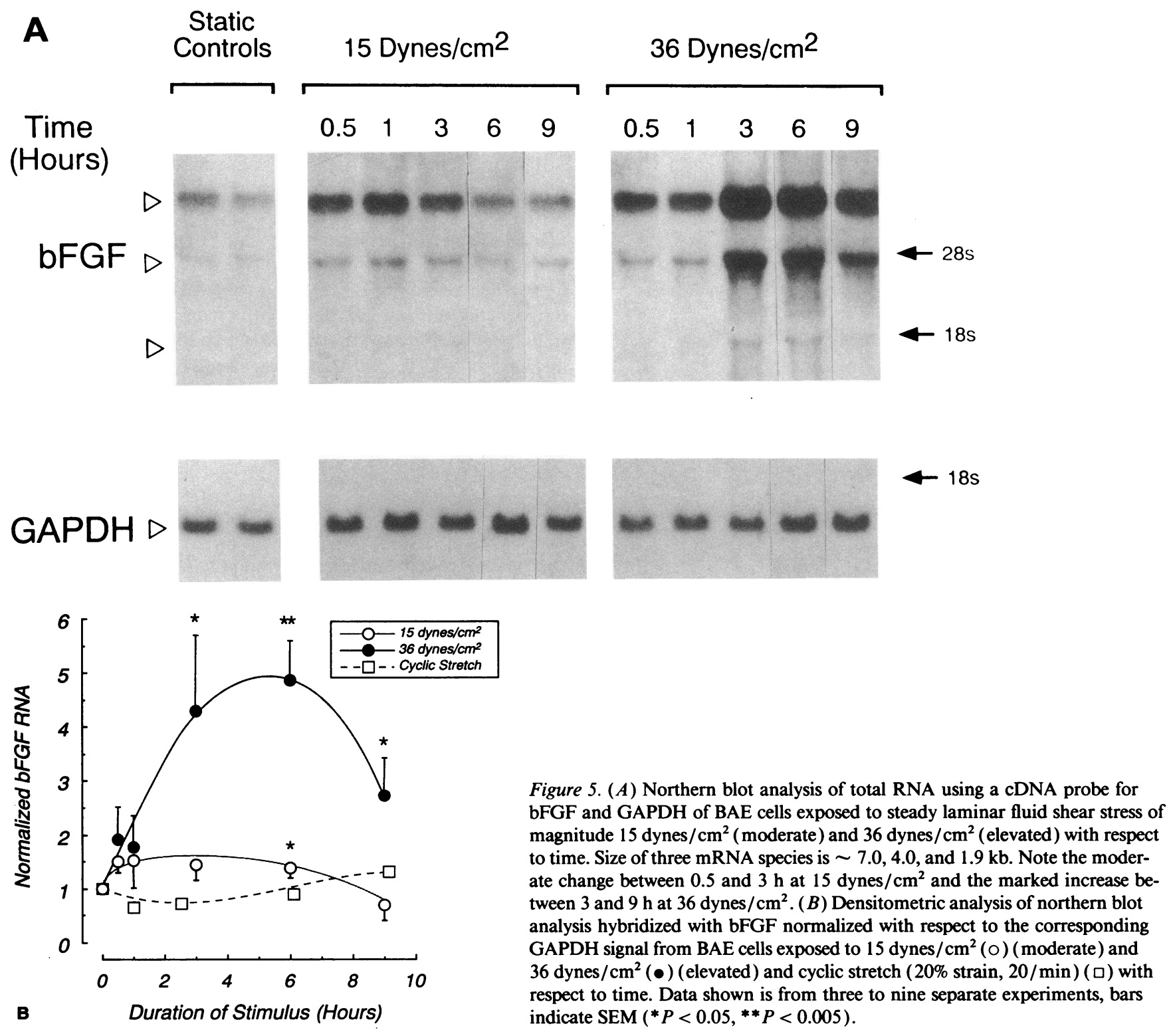

Hsieh et al. (46) using human umbilical vein cells reported that fluid shear stress induces a transient increase in both PDGF $A$ and $B$ chain mRNA that returns to baseline by $4 \mathrm{~h}$. In contrast our study showed that both physiological moderate $\left(15 \mathrm{dyn} / \mathrm{cm}^{2}\right)$ and elevated $\left(36 \mathrm{dyn} / \mathrm{cm}^{2}\right)$ shear stress induced a marked four- to fivefold decrease in PDGF B chain mRNA by $6-9 \mathrm{~h}$. The BAE cells, unlike HUVE cells, express the B but not the A chain of PDGF (39); the difference in the results may be due to the difference in cell origin. Furthermore, changes in mRNA levels were not reported for durations of shear $>4 \mathrm{~h}$, the time after which the downregulation reported in the present work is most significant. Some of our experiments have shown occasional increases $(\sim 50 \%)$ in PDGF B chain mRNA at times between 0.5 and $2 \mathrm{~h}$ but these were transient and not as prominent and as the long-lasting four- to fivefold decrease in PDGF $\beta$ chain mRNA observed after 6-9 h.

It is plausible that the decreased expression of PDGF B chain in response to physiological shear stress reported here may explain the property that freshly isolated BAE cells express

much lower (25-fold) levels of PDGF-B than when cultured in vitro under static conditions (47). It is interesting to note that PDGF-B mRNA levels behaved in a similar fashion to ET-1 in response to shear stress, exhibiting a significant four- to fivefold decrease, and a dependence on the time-average magnitude rather than the dynamic aspect of the shear stimulus. Both of these substances are vasoconstrictors and smooth muscle mitogens, and their decrease with shear stress raises the possibility of their involvement in the mechanism of the observed internal diameter decrease in response to chronically decreased blood flow and wall shear stress seen in vivo (6). Kraiss et al. (9), using rigid endothelialized polytetrafluoroethylene vascular grafts have recently reported that more smooth muscle infiltration and growth was observed in grafts exposed to low (11 $\mathrm{dyn} / \mathrm{cm}^{2}$ ) than to high ( $22 \mathrm{dyn} / \mathrm{cm}^{2}$ ) shear stress magnitude. The decrease of PDGF-B and ET-1 mRNA by shear stress may potentially be relevant to the observed differences since expression of PDGF-B and ET-1 would be higher in the endothelium exposed to the lower shear stress. Furthermore, the downregula- 


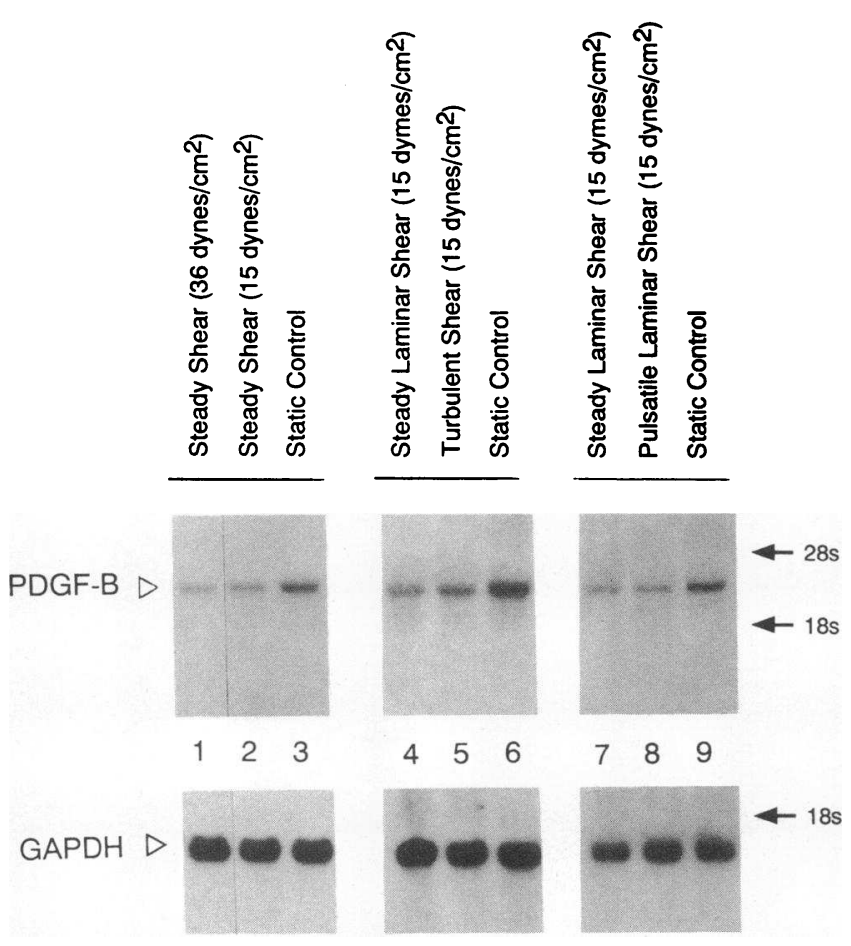

Figure 6. Representative northern blot analysis using a cDNA probe for PDGF-B (c-sis) of BAE cells exposed to steady laminar shear stress of 15 and 36 dynes $/ \mathrm{cm}^{2}$ and to turbulent and pulsatile laminar shear stress of 15 dynes $/ \mathrm{cm}^{2}$ time-average magnitude. Duration of shear stress exposure was $6 \mathrm{~h}$ for all experiments.
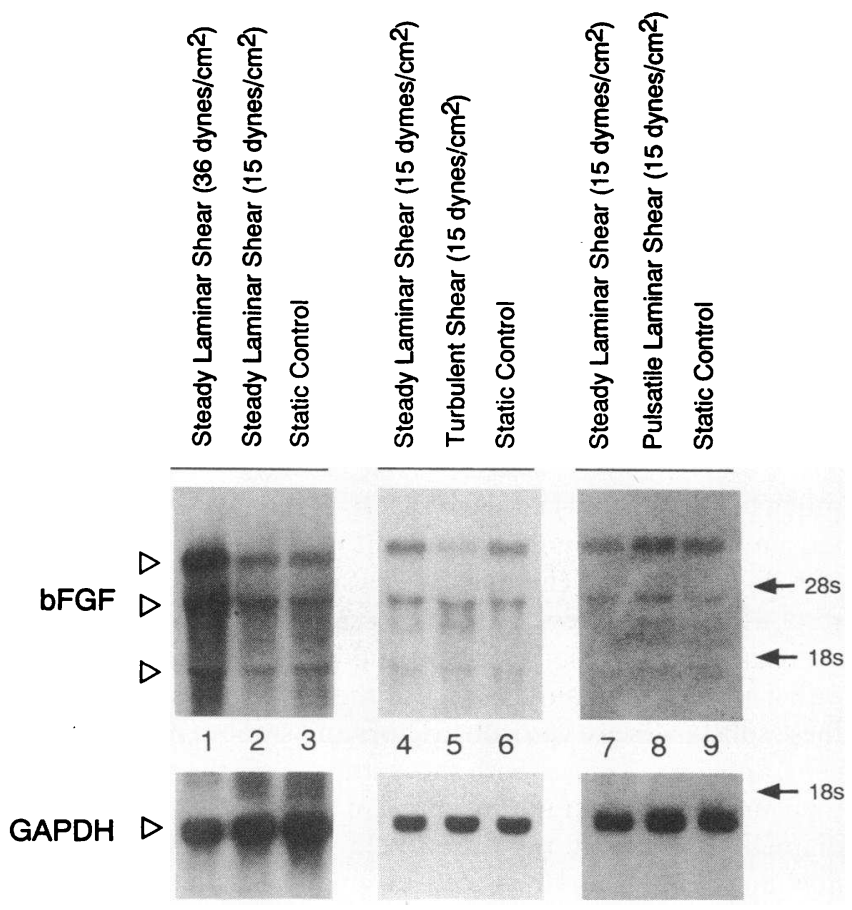

Figure 7. Representative northern blot analysis using a cDNA probe for bFGF of BAE cells exposed to steady laminar shear stress of 15 and 36 dynes $/ \mathrm{cm}^{2}$ and to turbulent and pulsatile laminar shear stress of 15 dynes $/ \mathrm{cm}^{2}$ time-average magnitude. Duration of shear stress exposure was $6 \mathrm{~h}$ for all experiments. Small variations in bFGF mRNA in turbulent (lane 5) and pulsatile (lane 8 ) were occasionally observed but were not significantly different from static controls in five other experiments (data not shown). tion of PDGF-B and ET-1 genes by shear stress may also be of interest in explaining the correlation of focal atherosclerotic lesions and intimal thickening seen preferentially in areas of low (0-4 dyn $\left./ \mathrm{cm}^{2}\right)$ but not higher $\left(15 \mathrm{dyn} / \mathrm{cm}^{2}\right)$ shear stress magnitude $(7,8)$.

The mechanism of the regulation of bFGF and PDGF-B mRNA levels by fluid shear stress is not at the present well understood. It is tempting to speculate that the mechanism of regulation of the ET-1 and PDGF B chain genes by shear stress may be shared to a certain extent because of their similar behavior in response to shear. We have recently shown that the shearinduced decrease in ET-1 mRNA in response to flow is a transcriptional event not associated with changes in ET-1 mRNA stability (48). Future work will have to address the molecular mechanism and second messenger involvement in the shear stress regulation of $b F G F$ and PDGF-B $m R N A$ and the potential significance of this phenomenon in flow-dependent vessel remodeling and atherosclerosis.

\section{Acknowledgments}

We thank Dr. T. J. Kulik for access to the cyclic stretch apparatus, and Drs. J. Fiddes and M. Mercola for providing bFGF and c-sis plasmids.

This work was supported by a Whitaker Foundation Grant to Dr. Izumo, by a Johnson \& Johnson Foundation Research Grant (through the Harvard-MIT Health Sciences and Technology Division) to Dr. Malek, and National Institutes of Health grants HL35610, HL35252, HL42663, and HL48638 to Dr. Dzau. Dr. Malek is supported by the National Institutes of Health Medical Scientist Training Program. Dr. Gibbons is a recipient of a Robert Wood Johnson Foundation Minority Faculty Development Award. Dr. Izumo is an Established Investigator of the American Heart Association.

\section{References}

1. LaBarbera, M. 1990. Principles of design of fluid transport systems in zoology. Science (Wash. DC). 249:992-1000.

2. Goldsmith, H. L., and V. T. Turitto. 1986. Rheological aspects of thrombosis and haemostasis: basic principles and applications. Thromb. Haemostasis. 55:415-435.

3. Kamiya, A., R. Bukhari, and T. Togawa. 1984. Adaptive regulation of wall shear stress optimizing vascular tree function. Bull. Math. Biol. 46:127-137.

4. Masuda, H., K. Kawamura, K. Tohda, T. Shozawa, M. Sageshima, and A. Kamiya. 1989. Increase in endothelial cell density before enlargement in flowloaded canine carotid artery. Arteriosclerosis 9:812-823.

5. Kamiya, A., and T. Togawa. 1980. Adaptive regulation of wall shear stress to flow change in the canine carotid artery. Am. J. Physiol. 239:H14-H21.

6. Langille, L., and F. O'Donnell. 1986. Reductions in arterial diameter produced by chronic decreases in blood flow are endothelium-dependent. Science (Wash. DC). 231:405-407.

7. Zarins, C. K., D. P. Giddens, B. K. Bharadjav, V. S. Sottiurai, R. F. Mabon, and S. Glagov. 1983. Carotid bifurcation atherosclerosis, quantitative correlation of plaque localization with flow velocity profiles and wall shear stress. Circ. Res. 53:502-514.

8. Asakura, T., and T. Karino. 1990. Flow patterns and spatial distribution of atherosclerotic lesions in human coronary arteries. Circ. Res. 66:1045-1066.

9. Kraiss, L. W., T. R. Kirkman, T. R. Kohler, B. Zierler, and A. W. Clowes. 1991. Shear stress regulates smooth muscle proliferation and neointimal thickening in porous polytetrafluoroethylene grafts. Arteriosclerosis. 11:1844-1852.

10. Mo, M., S. Eskin, and W. P. Schilling. 1991. Flow-induced changes in $\mathrm{Ca}^{++}$signalling in vascular endothelial cells: effect of shear stress and ATP. Am.J. Physiol. 260:H1698-H1707.

11. Dull, R. O., and P. F. Davies. 1991. Flow modulation of agonist (ATP)response $\left(\mathrm{Ca}^{2+}\right)$ coupling in vascular endothelial cells. Am. J. Physiol. 261 (1, part 2):H149-H154.

12. Shen, J., F. W. Luscinskas, A. Connolly, F. Dewey, Jr., and M. Gimbrone, Jr. 1992. Fluid shear stress modulates cytosolic free calcium in vascular endothelial cells. Am. J. Physiol. 262:C384-C390.

13. Nollert, M. U., S. G. Eskin, and L. V. McIntire. 1990. Shear stress increases inositol trisphosphate levels in human endothelial cells. Biochem. Biophys. Res. Commun. 170:281-287. 
14. Nollert, M. U., E. R. Hall, S. G. Eskin, and L. V. McIntire. 1989. The effect of shear stress on the uptake and metabolism of arachidonic acid by human endothelial cells. Biochim. Biophys. Acta. 1005:72-78.

15. Ziegelstein, R. C., L. Cheng, and M. C. Capogrossi. 1992. Flow-dependent cytosolic acidification of vascular endothelial cells. Science (Wash. DC). 258:656-659.

16. Franke, R., M. Gräfe, H. Schnittler, D. Seiifge, and C. Mittermayer. 1984. Induction of human vascular endothelial stress fibers by fluid shear stress. Nature (Lond.). 307:648-649.

17. Remuzzi, A., F. Dewey, Jr., P. Davies, and M. A. Gimbrone, Jr. 1984. Orientation of endothelial cells in shear fields in vitro. Biorheology. 21:617-630.

18. Cooke, J. P., J. S. Stamler, N. Andon, P. R. Davies, and J. Loscalzo. 1990. Flow stimulates endothelial cells to release a nitrovasodilator that is potentiated by reduced thiol. Am. J. Physiol. 28:H804-H812.

19. Diamond, S., S. Eskin, and L. McIntire. 1989. Fluid flow stimulates tissue plasminogen activator secretion by cultured human endothelial cells. Science (Wash. DC). 243:1483-1485.

20. Malek, A., and S. Izumo. 1992. Physiological fluid shear stress causes down-regulation of endothelin-1 mRNA in bovine aortic endothelium. Am. J. Physiol. 32:C389-C396.

21. Sharefkin, J. B., S. L. Diamond, S. G. Eskin, L. V. McIntire, and C. W. Dieffenbach. 1991. Fluid flow decreases preproendothelin mRNA levels and suppresses endothelin-1 peptide release in cultured human endothelial cells. $J$. Vasc. Surg. 14:1-9.

22. Vlodavsky, I., R. Fridman, R. Sullivan, J. Sasse, and M. Klagsbrun. 1987 Aortic endothelial cells synthesize basic fibroblast growth factor which remain cell-associated and platelet-derived growth factor which is secreted. J. Cell Physiol. 131:402-408.

23. Jawien, A. D. F. Bowen-Pope, V. Lindner, S. M. Schwartz, and A. W. Clowes. 1992. Platelet-derived growth factor promotes smooth muscle migration and intimal thickening in a rat model of balloon angioplasty. J. Clin. Invest. 89:507-511.

24. Barrett, T. B., and E. P. Benditt. 1988. Platelet-derived growth factor gene expression in human atherosclerotic plaques and normal artery wall. Proc. Natl. Acad. Sci. USA. 85:2810-2814.

25. Libby, P., S. J. C. Warner, R. N. Salomon, and L. K. Birinyi. 1988. Production of platelet-derived growth factor-like mitogen by smooth muscle cells from human atheroma. N. Engl. J. Med. 318:1493-1498.

26. Rifkin, D. B., and D. Moscatelli. 1989. Recent developments in the cell biology of basic fibroblast growth factor. J. Cell Biol. 109:1-6.

27. McNeil, P. L., L. Muthukrishnan, E. Warder, and P. D'Amore. 1989. Growth factors are released by mechanically-wounded endothelial cells. $J$. Cell Biol. 109:811-822.

28. Kandel, J., E. Bossy-Wetzel, F. Radvanyi, M. Klagsbrun, J. Folkman, and D. Hanahan. 1991. Neovascularization is associated with a switch to the export of bFGF in the multistep development of fibrosarcoma. Cell. 66:1095-1104.

29. Mignatti, P., T. Morimoto, and D. Rifkin. 1991. Basic fibroblast growth factor released by single, isolated cells stimulates their migration in an autocrine manner. Proc. Natl. Acad. Sci. USA. 88:11007-11011.

30. Williams, L. T. 1989. Signal transduction by the platelet-derived growth factor receptor. Science (Wash. DC). 243:1564-1570.

31. Berk, B. C., R. W. Alexander, T. A. Brock, M. A. Gimbrone, Jr., and C. R.
Webb. 1986. Vasoconstriction: a new activity for platelet-derived growth factor. Science (Wash. DC). 232:87-90.

32. Rubanyi, G. M., and L. H. P. Botelho. 1991. Endothelins. FASEB J. 5:2713-2720.

33. Masaki, T., and M. Yanagisawa. 1989. Molecular biology and biochemistry of the endothelins. Trends Pharm. Sci. 10:374-378.

34. Sdougos, H. P., S. R. Bussolari, and C. F. Dewey, Jr. 1984. Secondary flow and turbulence in a cone-plate device. J. Fluid Mech. 138:379-404.

35. Chomczynski, P., and N. Sacchi. 1987. Single-step method of RNA isolation by acid guanidium thiocyanate-phenol-chloroform extraction. Anal. Biochem. 162:156-159.

36. Abraham, J. A., A. Mergia, J. L. Whang, A., Tumolo, J. Friedman, K. A Hjerrild, D. Gospodarowicz, and J. C. Fiddes. 1986. Nucleotide sequence of a bovine clone encoding the angiogenic protein, basic fibroblast growth factor. Science (Wash. DC). 233:545-548.

37. Devare, S. G., E. P. Reddy, J. D. Law, K. C. Robbins, and S. A. Aaronson. 1983. Nucleotide sequence of the simian virus genome: demonstration that its acquired cellular sequences encode the transforming gene product $\mathrm{p} 23^{\text {sis }}$. Proc. Natl. Acad. Sci. USA. 80:731-735.

38. Mercola, M., C. Y. Wang, J. Kelly, C. Brownlee, L. Jackson-Grusby, C. Stiles, and D. Bowen-Pope. 1990. Selective expression of PDGF A and its receptor in early mouse embryogenesis. Dev. Biol. 138:114-122.

39. Collins, T., J. S. Pober, M. A. Gimbrone, Jr., A. Hammacher, C. Betsholtz, B. Westermark, and C. H. Heldin. 1987. Cultured human endothelial cells express platelet-derived growth factor A chain. Am. J. Pathol. 126:7-12.

40. Herman, I. M., A. M. Brant, V. S. Warty, J. Bonaccorso, E. C. Klein, R. L. Kormos, and H. S. Borovetz. 1987. Hemodynamics and the vascular endothelial cytoskeleton. J. Cell Biol. 105:291-302.

41. Adams, D. S. 1992. Mechanisms of cell shape change: the cytomechanics of cellular response to chemical environment and mechanical loading. $J$. Cell Biol. 117:83-93.

42. Olesen, S., D. E. Clapham, and P. F. Davies. 1988. Haemodynamic shear stress activates a $\mathrm{K}^{+}$current in vascular endothelial cells. Nature (Lond.). 331:168-170.

43. Diamond, S. L., J. B. Sharef kin, C. Dieffenbach, K. Frasier-Scott, L. V. McIntire, and S. G. Eskin. 1990. Tissue plasminogen activator messenger RNA levels increase in cultured human endothelial cells exposed to laminar shear stress. J. Cell. Physiol. 143:364-371.

44. Schweigerer, L., G. Neufeld, J. Friedman, J. A. Abraham, J. C. Fiddes, and D. Gospodarowicz. 1987. Capillary endothelial cells express basic fibroblast growth factor, a mitogen that promotes their own growth. Nature (Lond.). 325:257-259.

45. Edelman, E., M. Nugent, L. Smith, and M. Karnovsky. 1992. Basic fibroblast growth factor enhances the coupling of intimal hyperplasia and proliferation of vasa vasorum in injured rat arteries. J. Clin. Invest. 89:465-473.

46. Hsieh, H., N. Li, and J. Frangos. 1991. Shear stress increases endothelia platelet-derived growth factor mRNA levels. Am. J. Physiol. 260:H642-H646.

47. Barrett, T. B., C. M. Gajdusek, S. M. Schwartz, J. K. McDougall, and E. P. Benditt. 1984. Expression of the sis gene by endothelial cells in culture and in vivo. Proc. Natl. Acad. Sci. USA. 81:6772-6774.

48. Malek, A. M., A. L. Greene, and S. Izumo. 1993. Regulation of endothelin-1 gene by fluid shear stress is transcriptionally mediated and independent of protein kinase C and cAMP. Proc. Natl. Acad. Sci. USA. 90:5999-6003. 